\title{
THE EFFECT OF TWO TRADING INSTITUTIONS ON PRICE EXPECTATIONS AND THE STABILITY OF SUPPLY-RESPONSE LAG MARKETS
}

\author{
Michael D. JOHNSON * \\ The University of Michigan, Ann Arbor, USA \\ Charles R. PLOTT \\ The California Institute of Technology, USA
}

Received March 29, 1988; accepted February 20, 1989

\begin{abstract}
A series of four experimental markets are described which examine the effect that different trading institutions have on sellers' price expectations and market behavior. The results suggest that when sellers trade in information rich auction markets, their price expectations are relatively complex and adaptive. When sellers trade in more information poor posted price markets, their expectations are relatively simple and extrapolative. This difference in the complexity of expectations is reflected in the stability of the markets, the auction markets being more stable than the posted price markets. Overall the study supports the notion that trading institutions contribute to the observed complexity of price expectations.
\end{abstract}

\section{Introduction}

In the study of economic phenomena, sellers' price expectations affect the nature of market cycles and the potential for stable equilibria. Existing economic models of price expectation derive their predictions from general market conditions. Yet price expectations are formed under vastly different trading institutions, ranging from information rich auction markets to information poor posted price markets. Differences in trading institutions may help explain why price expectations are a 'rich and varied phenomena' that may not be captured by any one model (Lovell 1986: 120).

* Requests for reprints should be sent to M.D. Johnson, The University of Michigan, School of Business Administration, Ann Arbor, MI 48109-1234, USA. 
The present study examines the effect that different trading institutions have on price expectations and market stability within a series of experimental markets. Previous studies have demonstrated the systematic effect that trading institutions have on other aspects of market performance, such as price or market efficiency (cf. Plott and Smith 1978). The effect that institutions have on price expectations has not been addressed. We focus in particular on supply-response lag markets. Such markets are unique in that supply or quantity decisions are made in a time period prior to that in which the supply actually becomes available. Price expectations are very central to the functioning of markets with a supply-response lag, affecting both individual as well as market level behavior.

Our research addresses three specific questions. First, which of the price expectation models currently available best describes the stability, or instability, of supply-response lag markets? Second, which models best describe the behavior of individual sellers facing a supply-response lag? Finally, does the appropriateness of these models vary with the trading institution involved? In addressing these questions, the present study builds on recent research that has explored the variety of non-economic factors affecting price expectations, including individual differences (Blomqvist 1983), political preferences (Webley and Spears 1986), and media reporting (Pruitt et al. 1988). We begin by describing existing economic models of price expectation and their psychological complexity. We then describe the inherent differences in trading institutions and our predictions. Finally we examine expectations and market stability using naturally occurring market behavior under two very different exchange institutions, double-auctions and posted prices.

\section{Price expectations in supply-response lag markets}

A number of different models have been used to describe sellers' expectations and behavior in supply-response lag markets. Five prominent models, the traditional cobweb model, an extrapolative model, an adaptive model, a moving average rational expectations model, and Muth's (1961) original rational expectations model, exemplify increasing levels of judgmental complexity and market stability. 


\section{Traditional cobweb model}

The traditional theory of price expectations in supply-response lag markets is the cobweb model. According to the model, suppliers base their price expectations and resulting supply decisions on the observed market price in the immediately preceding period. That is:

$P_{t}^{e}=P_{t-1}$,

where $P_{t}^{\mathrm{e}}$ is the expected price in time $t$ and $P_{t-1}$ is the market clearing price in time $t-1$. This expectation function has important implications for market stability. The cobweb model predicts that when supply decisions are based on this expectation, both price and quantity

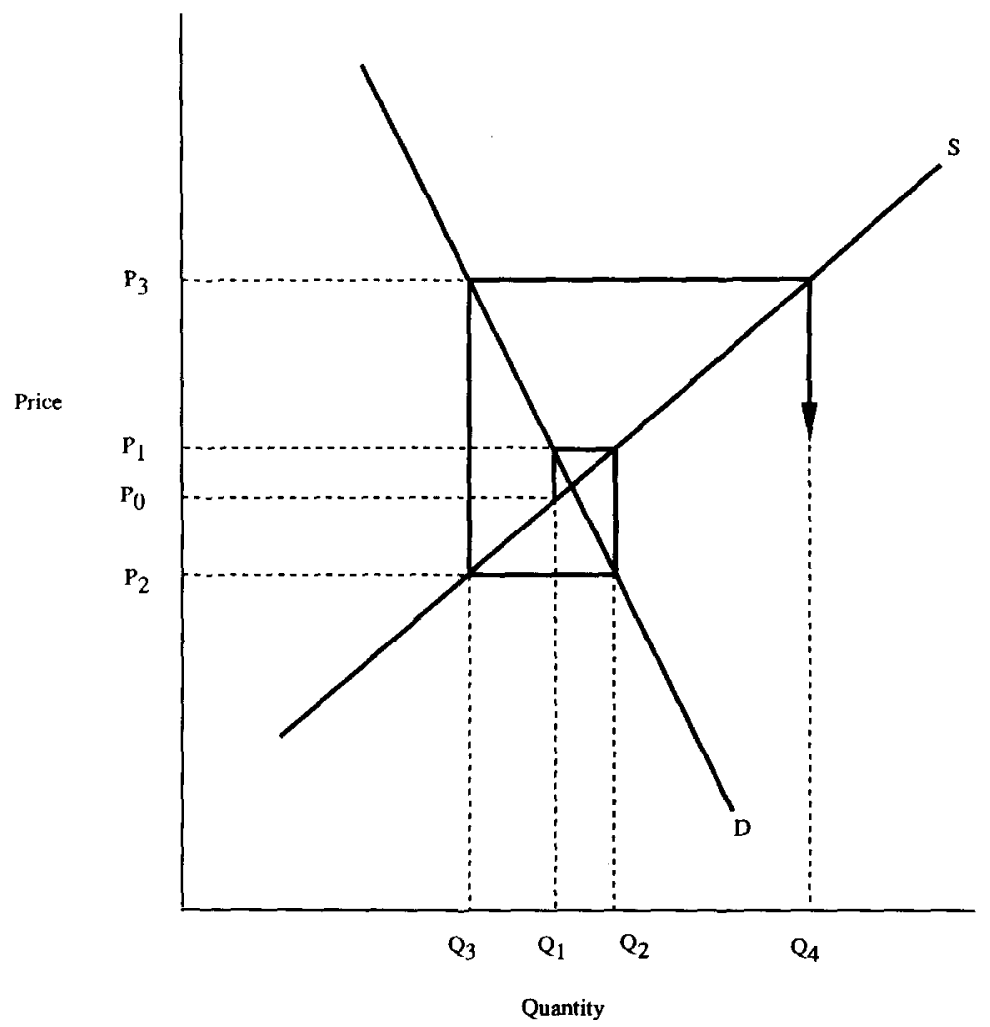

Fig. 1. Unstable cobweb. 
fluctuations result. These fluctuations are by definition two periods long and will increase or decrease in magnitude depending on the relative slopes of supply and demand (cf. Carlson 1967). Whenever demand is steeper than supply the result is long run market instability. This situation is depicted in fig. 1 for supply schedule $S$ and demand $D$ (adapted from Mansfield 1975).

An initial price $P_{0}$ results in a quantity supplied in period one of $Q_{1}$ and a resulting market clearing price of $P_{1}$. Price $P_{1}$, in turn, results in a quantity supplied in period two of $Q_{2}$ and a clearing price of $P_{2}$, and so on. Fluctuations in price and quantity continue to increase and the market fails to reach a stable equilibrium. When supply is steeper than demand, price and quantity fluctuations decrease rather than increase over time and the market eventually reaches a stable equilibrium.

\section{Extrapolative model}

The lack of long run cyclical instability in actual markets led to variations on the cobweb model to reconcile theory with data. Goodwin (1947) introduced a version of the cobweb model in which produccrs expect price to change by some constant factor times the most recent change in price. His expectation hypothesis can be stated as follows:

$P_{t}^{e}-P_{t-1}=-p\left(P_{t-1}-P_{t-2}\right)$,

where $-p$ is termed the 'extrapolative coefficient of expectation'. In the extrapolative model, prices in periods $t-1$ and $t-2$ determine the suppliers' expected price and resulting supply decisions. Price expectations are essentially a weighted average of prices over the past two market periods. As in the case of the traditional cobweb model, this expectation function will result in either long run stable or unstable two-period cycling depending on the relative slopes of supply and demand. Muth (1961: 272) shows that stability will result whenever demand is more than three times as steep as supply.

\section{Adaptive model}

As an alternative to both the traditional cobweb and the extrapolative variation, Nerlove (1958) postulated that suppliers more gradually 
change their expectations regarding price. Nerlove suggests that expected price is adjusted by how wrong the expected price was in the last period. The expected price in period $t$ is a weighted average of the last expected price and the most recent actual price with the weights summing to one:

$P_{t}^{e}=b P_{t-1}+(1-b) P_{t-1}^{e}$,

with $0<b<1$ where $b$ is referred to as the adaptive coefficient of expectation'. Carlson (1967) presents a geometric interpretation of this model in which a decrease in $b$ has the effect of rotating the demand curve counterclockwise, decreasing the absolute value of its slope and increasing the range of relative supply and demand slopes that should produce stable equilibriums. The traditional cobweb is a special case of the adaptive model when $b=1$.

A particular aspect of this model makes it qualitatively different from previous cobweb models. All past period observations are allowed some weight toward the current expectation. The model is more complex in its use of available market information or, put differently, less 'biased' in its dependence on $P_{t-1}$. The weight of past period observations must simply decline exponentially into the past. No matter how steep demand is relative to supply, there exists a sufficiently small coefficient of expectation that will produce stability. The inverse, however, does not hold. Given an adaptive coefficient of expectation, there will always exist supply and demand curves which predict unstable cobwebbing (Carlson 1967).

\section{Rational expectations models}

Two potential problems persist in the cobweb models outlined above. First, in every model price expectations are biased toward immediate past period prices. Of course the heaviest bias exists in the traditional model. The economic argument against the existence of a bias is quite simple. Such a bias would result in systematic forecasting errors and profitable opportunities for sellers of more accurate forecasts and thus be eliminated over time. A second more serious concern is that the two period long price and quantity fluctuations predicted by the cobweb models are rarely found. Observed cycles tend to be much longer (Pashigian 1970). 
The theory of rational expectations (Muth 1961) provides an alternative framework for analyzing supply-response lag markets without assuming biased price expectations. Under the rational expectations hypothesis, the mean price expectation of the firms in a market is simply the prediction made by the relevant economic theory (i.e., the law of supply and demand). Each actor or firm has an expectation and the economic equilibrium is the weighted arithmetic mean of these expectations.

$P_{t}^{*}=\left(P_{t 1}^{e}+P_{t 2}^{e}+\ldots . . P_{t n}^{e}\right) / n$

where $P_{t}^{*}$ is the equilibrium price in time $t, P_{t i}^{e}$ is the expected price in period $t$ by firm $i$ ( $i=1$ to $n$ ), and $n$ is the number of firms in the market. Put simply, Muth's rational expectations hypothesis predicts that the price in time $t$ is equal to the expected price in time $t$ which is equal to the market equilibrium price.

$P_{t}=P_{t}^{e}=P_{t}^{*}$.

The rational expectations prediction of market stability in supply-response lag markets is quite clear. Expectations should lead directly to an equilibrium or stable value. Instability, if observed, can only result from shifts or shocks in supply and/or demand causing a temporary disequilibrium.

However, Muth provides no description of the process by which rational expectations are realized. In response, Cyert and DeGroot (1974) introduced the concept of Bayesian revision of expectations into a rational expectations framework. According to their model, learning is continually taking place in the market. Priors are continually being modified as information is accumulated from period to period resulting in convergence toward the equilibrium price and quantity. Price expectations in this context are qualitatively equivalent to an equally weighted moving average of all previous market prices.

$P_{t}^{e}=\left(P_{1}+P_{2}+\ldots P_{t-1}\right) /(t-1)$.

Carlson (1968) hypothesized an expectation function along these same lines and proved that it leads to stable equilibrium conditions. When suppliers do not believe the market has changed and, as a result, 
they equally weight all previous observations, even supply-response lag markets must converge to equilibrium. Carlson argues that an 'invariably stable' cobweb holds whenever Walrasian stability conditions are satisfied. Auster (1970) extended Carlson's proof, arguing that even when Walrasian stability conditions fail to hold, supply-response lag markets with a moving average expectation function are stable whenever demand is bounded from above. Rational expectations does not imply the absence of price cycles. Any cycling should, however, be qualitatively different, in both origin and form, from that predicted by cobweb models. The cumulative effects of random shocks on supply and demand may cause 'apparent' cycles under rational expectations. These apparent cycles should be much longer than the two period cycles of a cobweb, and seldom less than four periods long (Pashigian 1970).

\section{The process behind the models}

The five models described above, from the traditional cobweb to rational expectations, represent increasingly complex expectations and associated market stability. The traditional cobweb model posits an extremely simple expectation function and is the most likely to produce instability. At the other extreme, the rational expectations models posit complex expectation functions and always predict stability. The extrapolative, adaptive, and moving average models are particularly attractive from a judgment process standpoint. All three are essentially information integration models of judgment and represent some degree of information 'averaging'.

Averaging models are very common in judgment research (cf. Anderson 1981). Part of their appeal stems from their underlying consistency with the psychological process of anchoring and adjusting (Einhorn and Hogarth 1985; Lopes and Johnson 1982). According to anchoring and adjustment (cf. Tversky and Kahneman 1974), people anchor their judgment on some salient aspect or piece of information and make adjustments to incorporate additional information. For example, in the extrapolative model sellers may anchor on $P_{t-2}$ and then adjust by taking into account $P_{t-1}$. In the adaptive model sellers may anchor on their expected price from the previous period and adjust for the actual price for that period. In the moving average rational expectations 
model the average of all past period prices may serve as an anchor that is updated or adjusted each period.

Although the adaptive and extrapolative models are 'biased' relative to rational expectations, they appear more plausible than the moving average model at an individual level. Given information processing limitations (Newell and Simon 1972), it is unlikely that all past period prices will be unit weighted in sellers' expectations as the moving average model dictates. The information processing requirements of the extrapolative and adaptive models are less extreme. The extrapolative model only requires that sellers consider prices from the previous two periods while adaptive expectations imply that sellers hold some existing expectation that they adjust based on currently available information (see Oliver and Winer (1987) and Winer (1985) for similar discussions). Therefore, one would expect the extrapolative and adaptive expectations models to be better predictors of individual level expectations. The experiments described shortly test the ability of each of these models to both predict market behavior and explain individual supply decisions.

\section{Empirical studies}

Existing research on price expectation has involved either surveybased data or controlled laboratory experiments. Although rational expectations is often invoked to explain the overall stability of markets, studies often find that micro-level (individual) behavior does not conform to rational expectations (Oliver and Winer 1987). While in some cases forecasts may be described as rational, in many cases forecasts are more consistent with adaptive or extrapolative expectation functions (Blomqvist 1983; see also Lovell (1986) for a review of relevant studies).

Two studies deserve particular mention because of their focus on price expectations in experimental markets. In the only existing experimental test of supply-response lag markets, Carlson (1967) showed some support for rational expectations. However, shortcomings of Carlson's study negate the significance of his results. First, in three of the four experiments Carlson conducted, the markets started (by accident) at essentially an equilibrium position. Ideally, any test of expectations and market stability should demonstrate the tendency of a market to reach an equilibrium. To do so, a market should start at a sufficient 
disequilibrium position. Second, Carlson examined only one particular trading institution, a posted one-price market. All subjects were sellers who made quantity decisions and received price feedback from a prespecified or passive demand curve.

More recently, Williams (1987) used computer-based double auction markets (that did not contain a supply-response lag) to study price expectations. He found price forecasts to be more consistent with adaptive expectations than with either rational or extrapolative expectations. Again, however, only one trading institution was employed. As argued earlier, expectations appear to be a rich and varied phenomena that may not be explained or described independent of the trading institution involved.

\section{Trading institutions and price expectations}

For our purposes, a trading institution is the procedure or rules under which transactions in a market are made and prices are determined. At one extreme, prices may result from a series of bids and offers by both buyers and sellers, as in the case of doublc-auction markets. At the other extreme, prices may simply be posted for buyers to accept or reject. Recall that expectation models derive predictions from 'general' market conditions, such as a supply-response lag, without considering the effect of specific trading institutions on expectations or stability.

However, a central principle of economic theory is that available information is, in fact, used. This suggests that the greater the range and quantity of market relevant information available to sellers, the more complex their expectations should become and the more likely or quickly the market as a whole will reach a stable equilibrium. For example, a double-auction market provides sellers with a wealth of information regarding the quantity and prices of units traded. In contrast, posted price markets restrict the amount and type of information available to sellers; sellers may only have access to a single posted or market clearing price and have no information regarding the total market supply. This suggests that relatively biased expectations and unstable supply-response lag markets are more likely under information restricted posted price trading than under information rich auction trading. 
Yet one must consider whether sellers are able to use the information that is available in a double-auction. Central to an information processing approach to judgment and choice is that individuals have a limited capacity to gather and process information (Lachman et al. 1979; Newell and Simon 1972). As the information available to form a judgment or make a choice increases, individuals may adopt simple rules and limit their information search in order to stay within their processing constraints. Studies by Lussier and Olshavsky (1979) and Payne (1976), for example, found subjects adopting simpler rules and using more incomplete information to make decisions among larger choice sets. An alternative prediction, therefore, is that sellers operating in simple posted price markets are more capable of using available information in their expectations than are sellers operating in more complex auction markets. Thus sellers' expectations may be more complex and markets more stable under posted price trading than under double-auction trading.

In the four experiments reported below, individual and market behavior was observed under both double-auction and posted price trading. This allows for a test between these competing predictions. We begin by describing the experiments and the overall performance of each market. We then model each sellers' expectations across the four experiments.

\section{Methodology and design}

In the present study, laboratory markets retaining the essential economic features of supply-response lag markets are used to test the applicability of the different economic models to individual and market behavior (Smith 1976; Plott 1982). Subjects participate as either buyers or sellers trading units of a commodity in a sequence of market trading periods. A major advantage of the methodology is that these markets meet the preconditions upon which the theories and their predictions are based. To say that laboratory markets are simulations of real markets and, hence, artificial approximations of the real thing would be false. Laboratory markets are fundamentally real in the sense that people earn income by engaging in organized trading activity.

Laboratory markets differ from naturally occurring markets in two ways. In laboratory markets, individual values (supply and demand) 
are controlled to meet the preconditions of economic theories. This control is accomplished by way of reward structures that induce prescribed monetary values on actions. A second difference centers on the trading institutions. Institutions in naturally occurring markets are in a constant state of evolution, affecting and being affected by the market. The two trading institutions used here, double-auctions and posted one-price markets, are held constant. This allows a more objective test of the relevant theories.

Particular supply and demand parameters are required in order to use the market level results of our experiments to test between the cobweb type models and the rational expectations models. Rational expectations models always predict stability. It is theoretically impossible for the supply-response lag nature of markets to cause instability under rational expectations. Any cobweb model, however, should predict instability as long as demand is sufficiently steep relative to supply. Recall that when demand is more than three times steeper than supply, both the traditional cobweb model and the extrapolative model predict instability. The adaptive model poses a different problem. Stability conditions under this model depend on the size of the adaptive coefficient of expectation. Predictions can only be determined after the fact. In each of the four experiments conducted here, demand is eight times steeper than supply. The adaptive coefficient will be estimated for each seller on the basis of individual supply decisions. If the estimated coefficients predict instability in the markets and they fail to be unstable, this would suggest rejecting the whole class of cobweb models in favor of rational expectations at the market level.

Experiments 1 and 2 use a double-auction trading institution in which buyers and sellers make bids and offers to buy and sell units of a commodity. Buyers and sellers are directly involved in the trading process. Experiments 3 and 4 utilize a passive one-price market. In these markets, sellers made quantity decisions and received feedback regarding the market clearing price from a passive demand curve. Sellers were not directly involved in the trading process. These two market institutions represent extremes in the involvement of sellers in the trading and, as a result, represent varying amounts of information available to sellers making supply decisions. It is reasonable to assume that most actual supply-response lag markets are either equivalent to or lie between these two extremes. A different group of subjects was used in each of the four experiments. These subjects were all drawn 
from the same population of graduate and undergraduate students at the University of Chicago.

\section{Experiment 1}

\section{Procedure}

In both experiments 1 and 2, six participants were sellers and six were buyers. Values for the units traded were established using Induced Value Theory (Smith 1976). Each seller received a marginal cost schedule containing the cost incurred for each unit sold. Each buyer received a similar schedule containing the value at which each unit purchased could be redeemed to the experimenter after the experiment. (See Plott (1982) for more details regarding the schedules and instructions used in these types of laboratory markets.) Each experiment consisted of a series of market trading periods. As mentioned, the institution used in experiment 1 was a double-auction. In each trading period, buyers were free to make oral bids to buy units and sellers were free to make oral offers to sell units. Each trading period lasted seven minutes. The currency used in the experiments was francs. All cost schedules, redemption values, bids and offers were stated in francs. At the end of the experiment, the subjects multiplied their total earnings in francs by an exchange rate to determine their earnings in dollars.

Expcriment 1 involved ten trading periods. In period one no supply-response lag was imposed on the sellers in order to familiarize both buyers and sellers with the trading procedure. Sellers (buyers) could sell (buy) as many units as they wished, one at a time, while continuing to make a profit. Beginning with period two and continuing through period ten, a supply-response lag was introduced. Sellers were required to make supply decisions prior to the beginning of each period. Once this decision was made, the sellers incurred the costs of all units declared for that period. Any unsold units represented a loss to the sellers equal to the marginal cost of those units.

A particular goal of our procedure was to create a disequilibrium state and then observe the tendency or failure of supply-response lag markets to reach an equilibrium. To do so, two different demand schedules were used. The supply and demand schedules used in all four experiments are shown in fig. 2. 


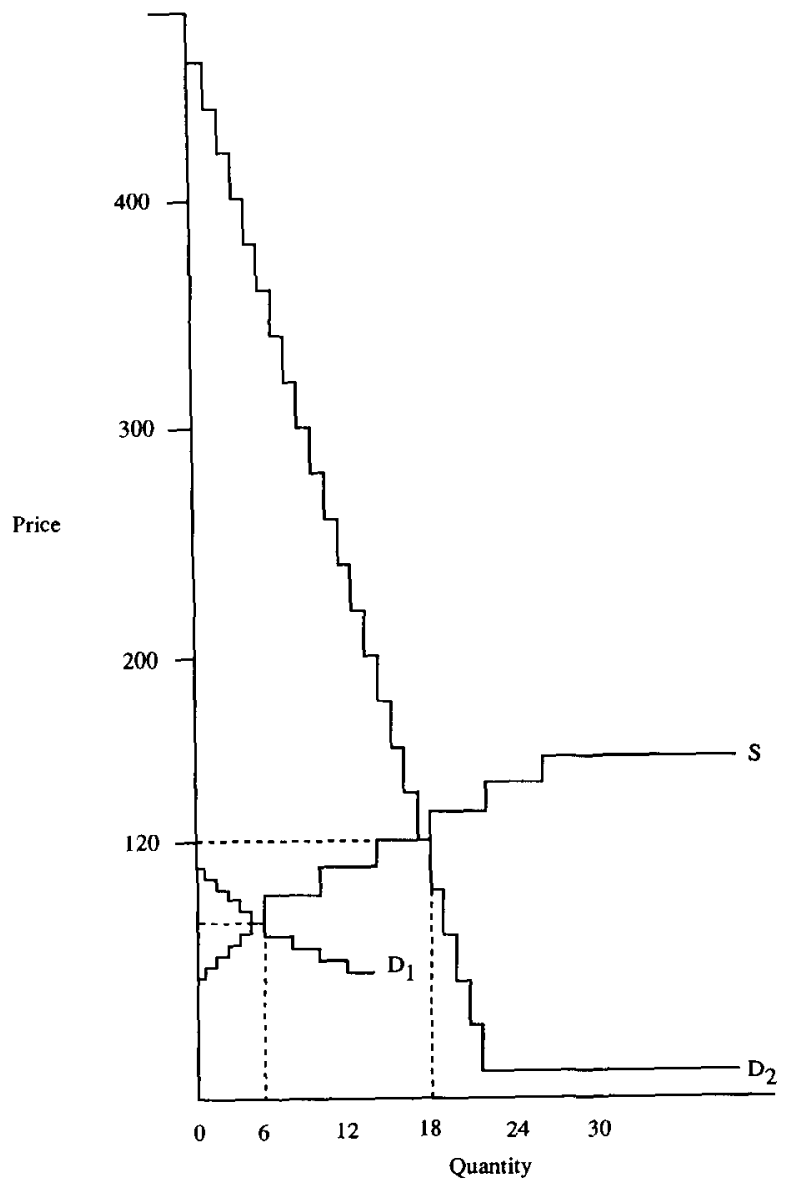

Fig. 2. Supply and demand parameters for experiments.

In trading periods one and two, the trial periods, sellers faced supply $S$ and buyers faced Demand $D_{1}$ (equilibrium $p=90, q=6$ ). ${ }^{1}$ In periods three through ten, the experimental periods, sellers faced supply $S$ (slope $=0.5)$ and buyers faced demand $D_{2}($ slope $=-4$ ). Shifting the demand parameters from the trial to the experimental periods was intended to start the experimental periods at a sufficient disequilibrium position. If rational expectations is correct, price and quantity should

\footnotetext{
${ }^{1}$ In experiment 1 , sellers actually faced a constant cost schedule of 90 francs over the first six units sold. Experiments 2, 3 and 4 operated under the exact supply schedule in fig. 2 .
} 
converge to their long run equilibrium values $(p=120, q=18)$. If supply-response lag markets follow cobweb model predictions, price and quantity should fluctuate systematically around the equilibrium
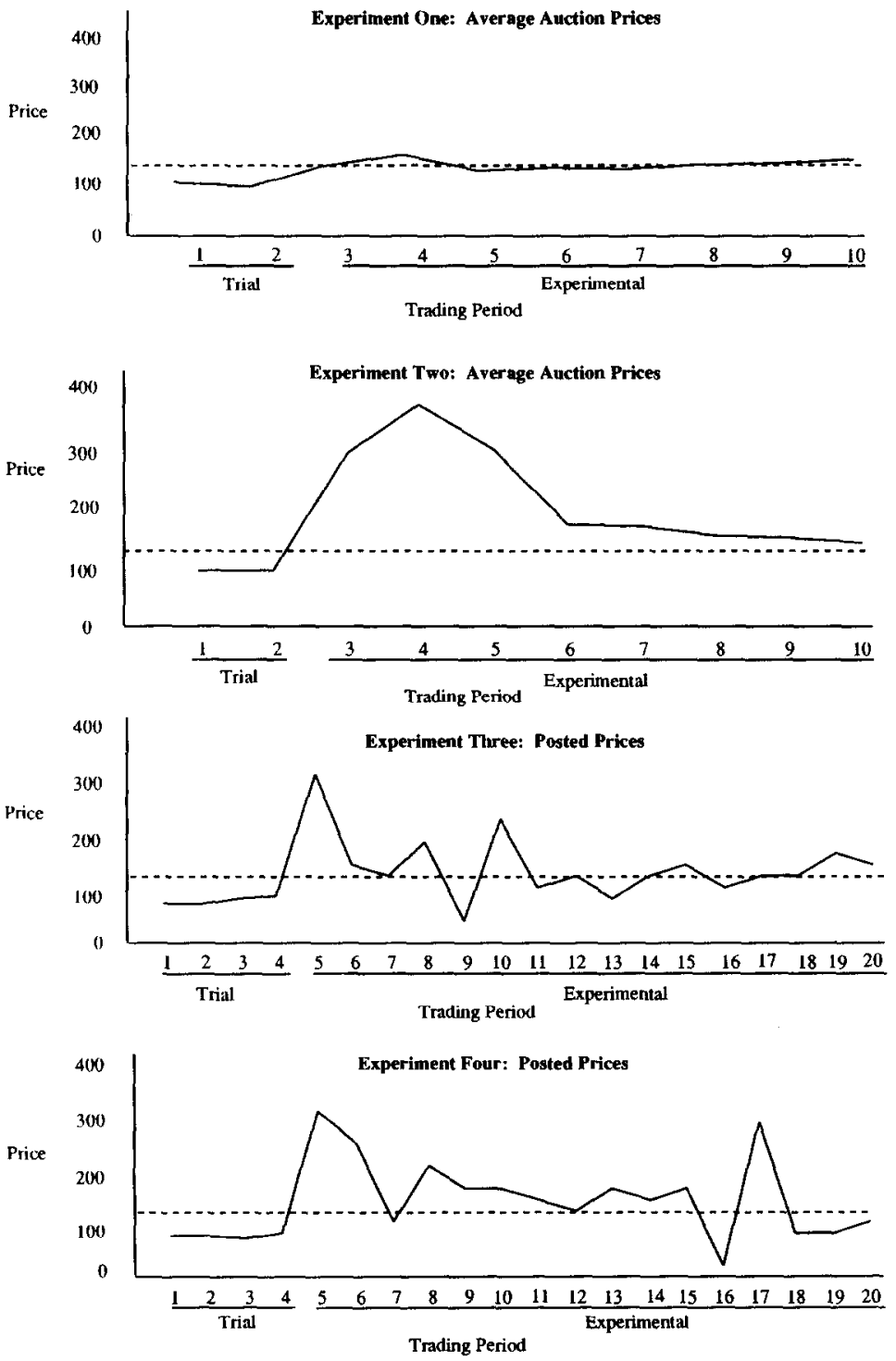

Fig. 3. Contract prices across experiments. 
price and quantity in two period long cycles. These fluctuations should increase over time resulting in an unstable market.

\section{Results}

The average contract prices for experiment 1 are presented at the top of fig. 3. (The dotted line represents the equilibrium price of 120.) The results reveal a clear tendency for market stability over time. After a period of initial instability following the parameter shift, market prices converge toward and remain close to the rational expectations equilibrium in subsequent periods. This long run price stability is mirrored by reasonable stability in both individual and aggregate quantity decisions. The table reports the individual quantities and total market supply by period. Here too an initial period of instability is followed by general convergence. (In equilibrium, each seller should be supplying three units.)

Market supply in any given period implies a corresponding short run equilibrium price. These short run price predictions, along with the average prices, are presented in the table. What is interesting is that changes in the overall quantity supplied from period to period did not drastically affect prices. Under the supply and demand parameters of this market, small deviations in quantity supplied away from the equilibrium value imply rather large deviations in short run equilibrium prices. However, price remained close to the rational expectations or long run equilibrium despite short run economic predictions.

The market in experiment 1 was fairly efficient. In an experimental context, market efficiency refers to the amount of money earned by the market participants relative to the maximum amount that could be extracted from the experimenter. For the supply-response lag markets in experiments 1 and 2, efficiency was measure as the amount of money extracted as a percentage of possible earnings given the quantity supplied in each period. By the third experimental period (period 5), efficiency (not shown) converged and remained close to $100 \%$.

\section{Experiment 2}

\section{Procedure}

At least at the market level, experiment 1 supports the stability of supply-response lag markets and the rational expectations hypothesis. 


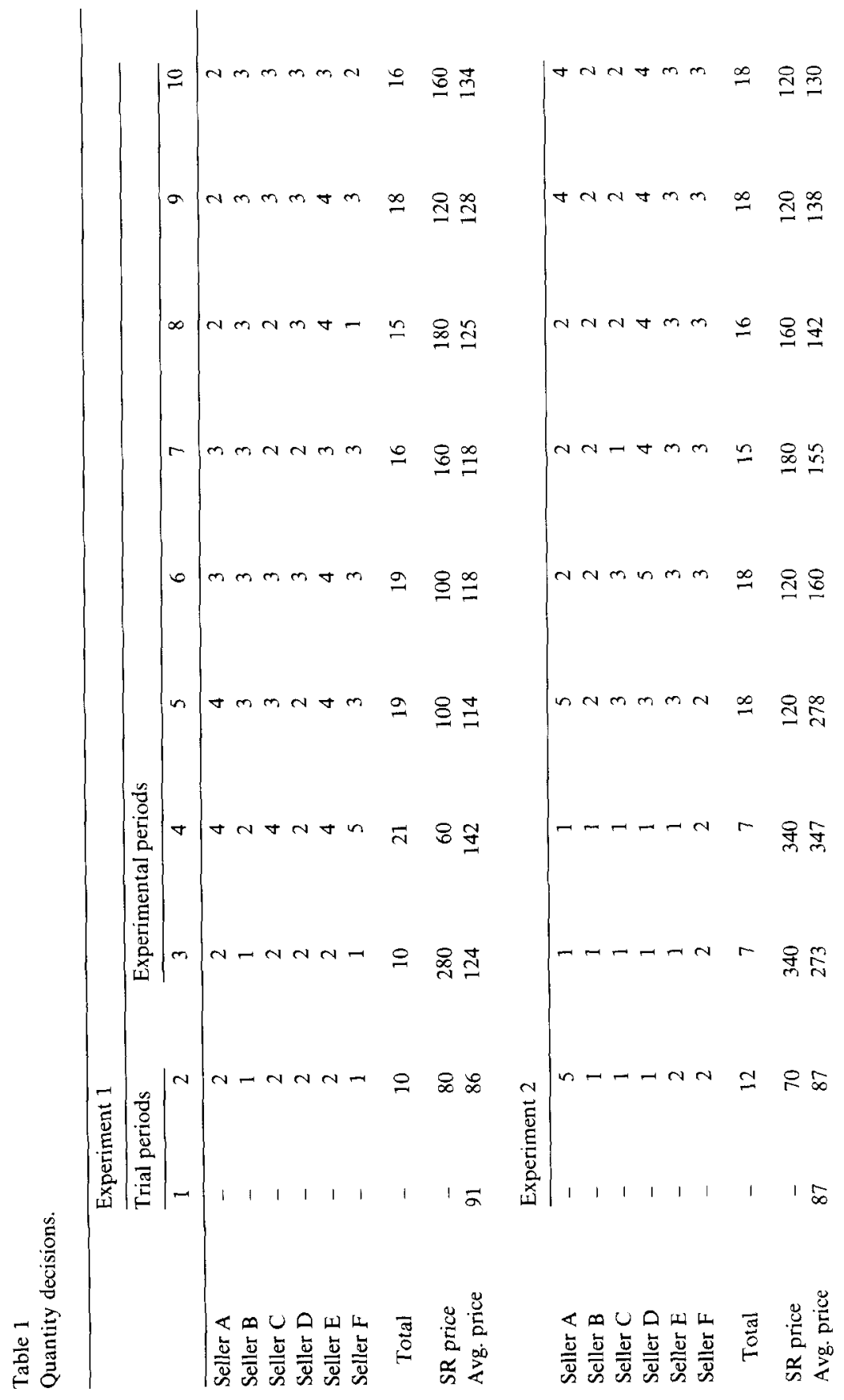




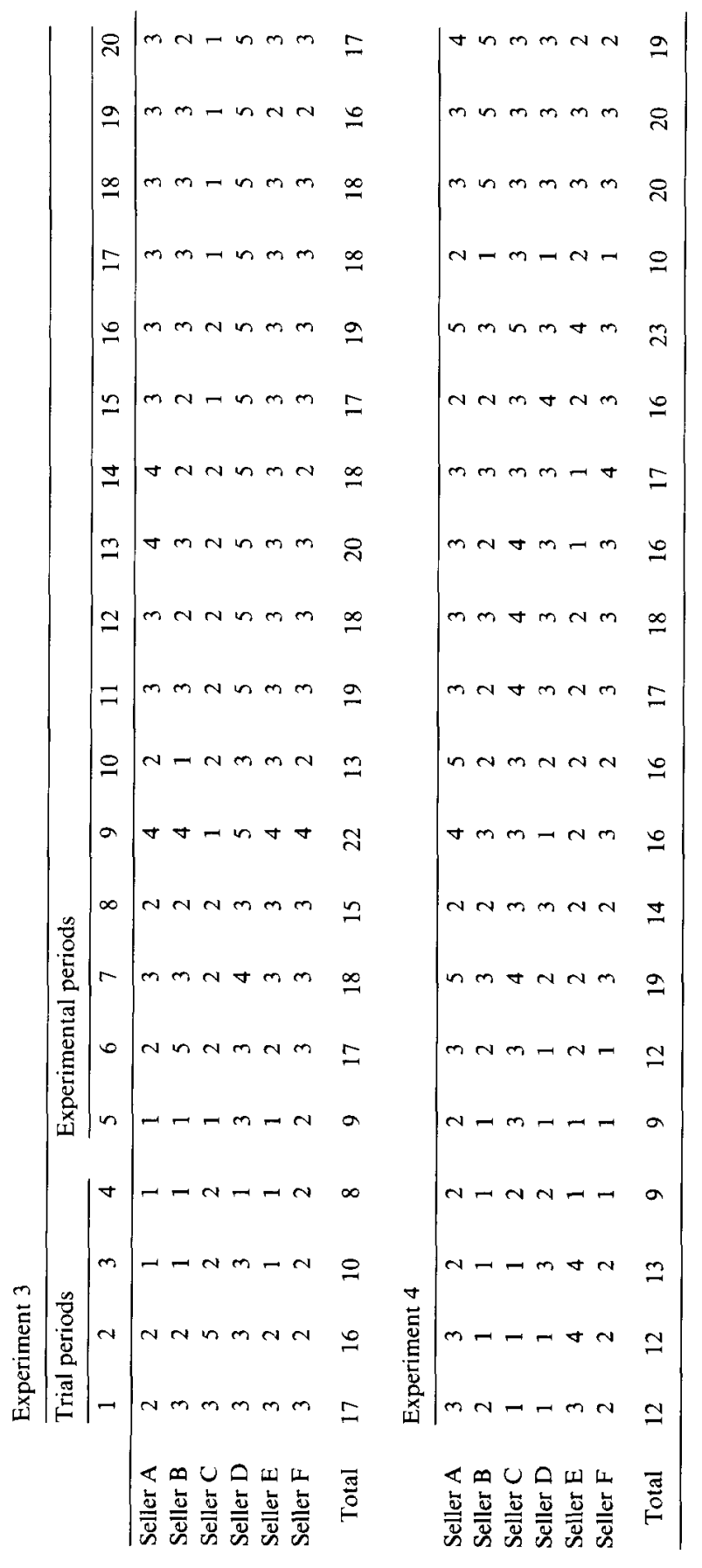


However, a potential problem with experiment 1 was the failure of short run prices to adjust to short run changes in demand. This phenomenon limited the disequilibriating effects of the trial period parameters. There seem to be two possible causes for this phenomenon. Sellers may have been 'soft' in accepting bids because of inadequate sales incentives under the trial period parameters. (As described in footnote 1 , the supply schedule was flat for sellers over the first six units sold in experiment 1.) The increased seller profits early in the experimental periods may have appeared quite satisfactory compared to trial period earnings. A second possible cause relates to the parameter shift itself. Price may eventually reach the short run equilibrium given sufficient time to adjust to the change. The lack of adjustment in experiment 1 may have contributed to the market's stability.

Experiment 2 replicates experiment 1 while correcting for these potential problems. Experiment 2 differs from experiment 1 in the following respects. First, sellers' costs for the first five units supplied were reduced to correspond with the supply curve in fig. 2 . This should provide sellers with more adequate incentives during the trial periods. Second, the quantity decisions for experimental period 1 (period 3) were held constant for the first two experimental periods (periods 3 and 4). Third, the subjects were told that a parameter shift had occurred. Informing the buyers and sellers of a change and allowing short run price more time to adjust to the initial disequilibrium position should avoid the potential problems confronted in experiment 1 . Finally, a new sample of buyers and sellers was recruited.

\section{Results}

The average contract prices by period, shown in fig. 3, again reveal a clear tendency for stability and support for the rational expectations hypothesis at the market level. Similar to experiment 1 , a period of initial instability following the parameter shift is followed by convergence to the long run equilibrium. Moreover, most of the initial instability can be attributed to the disequilibriating effects of the trial period parameters. The procedural changes instituted in this experiment accomplished their objective. Referring to table 1, short run prices adjusted to the short run equilibriums early in the experimental periods. The quantity decisions, similar to those in experiment 1 , became increasingly stable over time. And once again the market was 
efficient. By period six, market efficiency (not shown) was at the $95 \%$ level.

\section{Experiments 3 and 4}

\section{Procedure}

Sellers in the double-auctions of experiments 1 and 2 witnessed the transaction price for each unit traded. This gave them access to both aggregate quantity and substantial price information. The information available to sellers in a posted one-price market, in contrast, is limited to their own quantity supplied and the market clearing one-price. Experiments 3 and 4 replicate experiments 1 and 2 using a passive one-price trading institution.

Sellers in the experiments faced the same parameters as in experiment 2. These parameters should place the markets in an initial disequilibrium position. Short run price in a passive one-price market adjusts automatically to the level of demand that clears the market. This avoids the short run adjustment problems encountered in experiment 1 . The automatic adjustment also allows for more observations (trading periods) under the experimental parameters.

In each experiment six participants were sellers in a sequence of market trading periods. A new sample of subjects was used in each experiment and unit values were again established using Induced Value Theory. Before the beginning of each period, sellers made their supply decisions and the costs for units supplied were incurred at that point. Once the sellers made their decisions, the experimenter aggregated the supplies (without revealing the aggregate supply to the sellers) and determined the market clearing one-price. Sellers recorded this price as the contract price for all units supplied and calculated their earnings. This process continued for twenty periods. In trading periods one through four, sellers faced demand $D_{1}$. In the experimental periods, trading periods five through twenty, sellers faced demand $D_{2}$ (equilibrium quantity $=18$, price $=120$ ). As in experiments 1 and 2 , the trial periods familiarized the subjects with the procedure and served to start trading at a disequilibrium position when the parameter shift occurred. Unlike experiment 2 , it was unnecessary to hold quantity decisions constant from the first to the second experimental period. 
Again, rational expectations predicts price and quantity will converge to their equilibrium values while the cobweb models predict systematic fluctuations around price and quantity. These fluctuations should be two periods long and increase over time resulting in long run market instability. Our prediction is that limiting the available information by instituting posted price trading should result in a decrease in the complexity of price expectations and associated market instability.

\section{Results}

The short run market clearing prices for experiments 3 and 4 are presented in fig. 3. Although the markets in experiments 3 and 4 generally converged toward equilibrium, price and quantity fluctuated in two-period cycles more than they did in experiments 1 and 2. There are brief periods of cobweb like cycling in both of the posted price markets, though no prolonged cycling occurs. Overall the results of all four experiments fail to support the long run instability predicted by the cobweb models. At the same time, and consistent with our initial prediction, posted price markets appear less stable than double-auction markets.

\section{Model estimations}

In this section we examine each model's ability to explain each seller's quantity decisions. Assuming that each subject was acting to maximize profits, it is possible to derive expected prices from the subjects' quantity decisions. Expected price is simply that which maximized expected profits for the actual quantity supplied in any given period. ${ }^{2}$ These expected prices, along with the actual prices in the market, allow us to estimate each model for each subject. This resulted in 6 (sellers per experiment) by 4 (experiments) by 5 (competing models) or 120 estimations. Estimating the adaptive expectations model also provides this model's market level predictions.

\footnotetext{
${ }^{2}$ Our use of implicit, behavior-based estimates of price expectation rather than explicit price forecasts is consistent with Carlson's (1967) study. Williams (1987), in contrast, used explicit forecasts to model price expectations. Our double-auction results and model estimations are very similar to Williams, suggesting that both approaches are reasonable.
} 
Analysis

Each subject's quantity decisions were used to derive estimations of their expected price in each experimental period of each experiment. For experiments 1 and 2, the actual price in each period was assumed to be the average of all the contract prices observed during that period. ${ }^{3}$ For experiments 3 and 4 , the actual price in each period is simply the short run market clearing price.

The traditional cobweb model was tested by estimating a linear regression function of the form:

$P_{t}^{e}=a+b\left(P_{t-1}\right)+n_{t}$,

where $a$ is a constant and $n_{t}$ is an independent and identically distributed random variable with zero mean and finite variance. (These assumptions are implicit in all further analyses.) The extrapolative model was tested by estimating a linear function of the form:

$P_{t}^{e}-P_{t-1}=a-b\left(P_{t-1}-P_{t-2}\right)+n_{t}$.

The adaptive expectation model was tested by estimating a linear function of the form:

$P_{t}^{e}-P_{t-1}^{e}=a+b\left(P_{t-1}-P_{t-1}^{e}\right)+n_{t}$.

Recall that under our supply and demand parameters, this model predicts instability when the adaptive coefficient, $b$, is greater than 0.22 . Muth's original rational expectations model was tested by estimating a linear function of the form:

$P_{t}=a+b\left(P_{t}^{e}\right)+n_{t}$.

In its strictest form, Muth's model predicts that $a$ should equal zero while $b$ should equal one (Lovell 1986). Finally, the moving average

\footnotetext{
${ }^{3}$ Alternatively one could argue that the relevant price for each subject in each period is either the average selling price of that subject's own units or the short run market clearing price for that period. The models were estimated under all three price assumptions and the sensitivity of the results examined. Overall the pattern of results and their significance did not vary with the price assumption.
} 
rational expectations model proposed by Cyert and DeGroot was tested by estimating a linear function of the form:

$$
P_{t}^{e}=a+b\left[\left(P_{1}+P_{2}+\ldots P_{t-1}\right) /(t-1)\right]+n_{t} .
$$

Again, each model was estimated for each individual seller in each experiment for a total of 120 estimations.

Only a subset of the experimental periods were included in the estimation of particular models. The overriding criterion here was to estimate each model using parameter estimates based only on information from the experimental periods. Muth's rational expectations model, which presumes no lag, was tested using all of the experimenal periods. The traditional cobweb model, the adaptive model, and the moving average rational expectations model, all of which require parameter estimates from time period $t-1$, were estimated using $n-1$ observations (where $n$ is the number of experimental periods). The extrapolative model, which requires parameter estimates from time periods $t-1$ and $t-2$, was estimated using $n-2$ observations. Because supply decisions were held constant for the first two experimental periods of experiment 2 , the first of these periods was ignored. Of the 120 possible estimations, 8 could not be estimated due to a lack of variance in one or more parameters over the experimental periods leaving 112 usable estimations.

The dependent measure of interest is the fit of each regression model as reflected by the squared correlation coefficient. Whereas $R$-squared reflects the variance explained by the model, a simple correlation coefficient has no such clear-cut, intuitive interpretation (Neter and Wasserman 1974: 90). However, different models make different predictions regarding the direction of the relationships described in eqs. (7) through (11). For example, the extrapolative model in eq. (8) predicts a negative coefficient on $\left(P_{t-1}-P_{t-2}\right)$, while the adaptive model in eq. (9) predicts a positive coefficient on $\left(P_{t-1}-P_{t-1}^{e}\right)$. Looking only at $R$-square does not take into account whether or not the direction of the hypothesized relationship was confirmed. Therefore, the $R$-square fit measures were adjusted to reflect whether or not the estimated relationships were in the predicted directions. The $R$-squares were assigned a positive value as long as the estimated relationships were in the direction predicted by the models and assigned a negative 
value if the estimated relationships were in the opposite direction from what was predicted.

An analysis of variance model, using a general linear models procedure, was estimated in order to test for significant differences in fit across the five models and the two trading institutions. The critical independent variables in the analysis were the economic model estimated (Cobweb, Extrapolative, Adaptive, Moving Average Rational Expectations, or Muth Rational Expectations), the type of institution involved (Double-Auction or Posted Price), a model by type of institution interaction, and a random effects variable for experiments 1 through 4 (nested within type of institution). Again, we predict that the more complex expectations models are more applicable in the more complex double-auction markets. Alternatively, if subjects faced severe information processing constraints then the opposite may hold; the more complex models may be more applicable in the simpler, posted price markets. In either case the prediction is a significant interaction between the model estimated and the type of institution.

\section{Results: Model fits}

The analysis of variance results reveal a significant difference in fit across models $(F=46.57, p<0.001)$. The average fits equaled 0.042 for the traditional cobweb model, 0.356 for the extrapolative model, 0.501 for the adaptive model, -0.005 for the moving average model, and -0.363 for Muth's model. Notice that these average fits, ordered from the simplest expectation function of the cobweb model to the most complex expectations of Muth's model, are non-monotonically related to the complexity of the expectation functions. Sellers' expectations, though more complex than those assumed by the traditional model, do not appear as complex as those assumed by rational expectations. The adaptive and extrapolative models provide the best descriptions of the implicit price expectations. Muth's model is the lowest scoring model on our fit index. In fact, the negative average fit of Muth's model supports a negative rather than positive relationship between actual and expected prices, or 'irrational' expectations. Of the 23 subjects for which this model could be estimated, 20 showed a negative relationship between actual and expected price. The overall superior fit of the adaptive model is consistent with William's earlier 


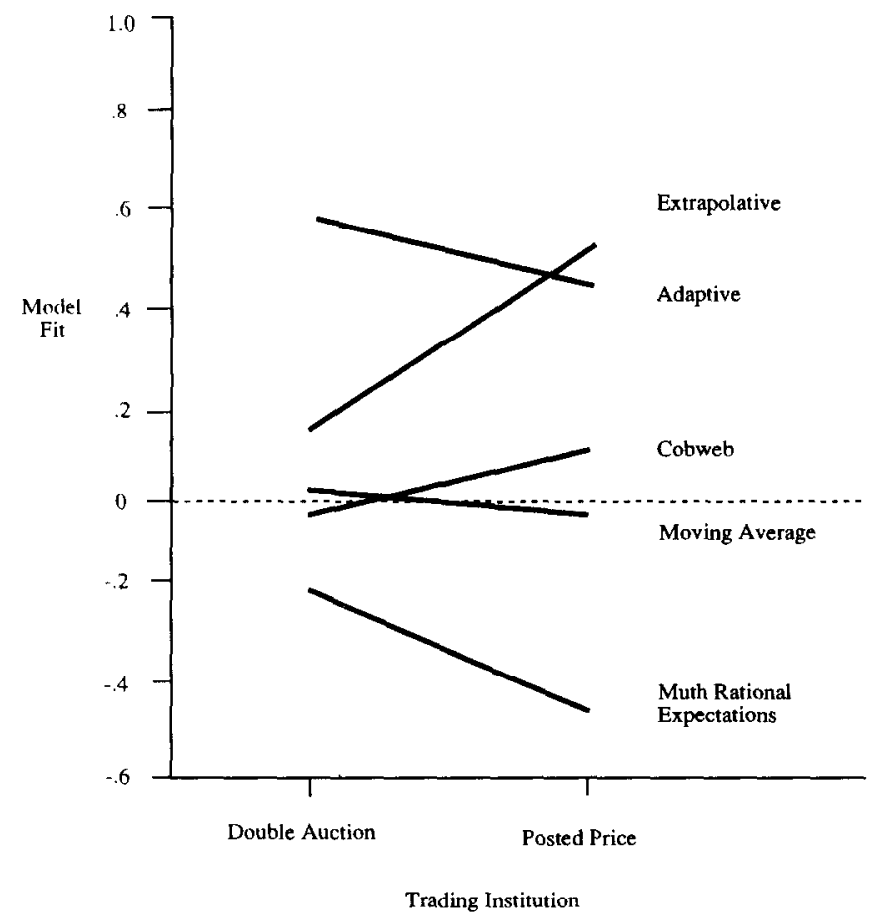

Fig. 4. Model fit by institution.

experimental results as well as the results of several survey-based studies described by Lovell (1986).

The important result is the model by type of institution interaction effect depicted in fig. 4 ( $F=6.03, p<0.001)$. Driving the interaction is a reduction in fit for the three most complex models (adaptive, moving average, and Muth rational expectations) and a corresponding increase in fit for the two simpler models (traditional cobweb and extrapolative) from the auction markets to the posted price markets. This is consistent with our initial prediction. Of the remaining independent variables in the analysis of variance, type of institution had no simple main effect on model fit, and experiment 1 differed from experiment 2 ( $F=$ $29.74, p<0.001$ ), probably due to the procedural differences in the two experiments. There was no significant difference between experiments 3 and 4 . The overall analysis of variance model $R$-square was 0.84 . 
The model by type of institution interaction is very evident for the superior fitting adaptive and extrapolative models. The extrapolative model, the simpler or more biased of the two, improves in fit from the complex double-auction markets of experiments 1 and 2 to the simple posted price markets of experiments 3 and 4 . In contrast, the fit of the more complex adaptive expectations model decreases. A separate analysis of variance including only these two models again reveals the predicted model by type of institution interaction $(F=16.82, p<$ $0.001)$.

\section{Results: Model coefficients}

Under the experimental parameters of the four experiments, the adaptive expectations model predicts instability only when the adaptive coefficient of expectation exceeds 0.22. Despite the large difference in slopes for supply and demand in the experiments, the estimates of the adaptive coefficient averaged $0.92,0.13,0.16$, and 0.16 respectively for experiments 1 through 4 . Thus the adaptive model and the rational expectations models all predict stability in experiments 2, 3 and 4 . Recall that in strict form, Muth's model predicts a constant $(a)$ equal to zero and a coefficient $(b)$ equal to one. The average estimated constant and coefficient were not as predicted. The average constant (379.14) was significantly greater than zero and the average coefficient $(-2.097)$ was significantly less than one $(p<0.001)$. These results are consistent with the observed poor fit of Muth's model at the individual level.

\section{Summary and conclusions}

Price expectation models vary from simple and biased cobweb models to complex rational expectations models. The present study examined the ability of different economic models of price expectation to explain both market and individual behavior within four experimental supply-response lag markets. Two markets were operated under an information rich double-auction trading institution while two operated under more information restricted posted price trading.

Contrary to the predictions of both the traditional cobweb model and an extrapolative expectations model, all four experimental markets 
were relatively stable as price and quantity converged toward the long run economic equilibrium. These market level results are very consistent with the rational expectations hypothesis. It appears that both the traditional cobweb and extrapolative expectations can be rejected in favor of rational expectations as a model of market behavior. The adaptive model predicted instability only in experiment 1 . While this provides some evidence to reject the model at the market level, this conclusion is obviously tentative.

Although rational expectations explains the general convergence of the markets toward equilibrium, it does not explain the relative instability of the posted price markets compared to the double-auction markets. It also fails to describe the behavior of individual sellers. Both Muth's (1961) 'black box' model and Cyert and DeGroot's (1974) moving average model were very poor at explaining sellers' quantity decisions. At a micro-level, rational expectation does not appear to explain the behavior observed here. This result is consistent with previous studies (cf. Lovell 1986).

The main contribution of the present study is the observed dependence of individual expectations and market stability on the trading institution. Across the four experiments described here, an adaptive expectations model provides the best description of sellers' behavior under double auction trading markets while an extrapolative expectation model best describes sellers' behavior under posted price trading. The difference in the complexity of the sellers expectations was evident from the overall behavior of the markets. As predicted, sellers' expectations were more complex and market behavior more stable under information rich auction trading than under information restricted posted price trading.

From a psychological standpoint, the superiority of the adaptive and extrapolative models at explaining individual behavior is not surprising and is generally consistent with previous findings (Blomqvist 1983). Both of these models represent variations on the averaging models often found in studies of human judgment (Anderson 1981), they are both consistent with an anchoring and adjustment process, and both make reasonable demands on sellers's information processing.

Overall the study provides three conclusions. First, rational expectations explains the observed stability of supply-response lag markets. Second, individual behavior is more consistent with averaging rules of intermediate complexity, particularly adaptive and extrapolative expec- 
tations. Finally, individual seller behavior and resulting short run market stability appear critically linked to the trading institution involved.

Naturally these conclusions are tentative and require further investigation. The four experiments presented here are limited and represent the behavior of a relatively small sample of 24 sellers, 6 in each experiment. The sample itself was obtained from a relatively sophisticated population of graduate and undergraduate university students. Further examinations involving a different population or populations of sellers would obviously strengthen our conclusions. At the same time, the individual level expectations revealed here were no more or less complex that those found in previous studies (Blomqvist 1983) suggesting that our particular subject population did not systematically affect our results.

Our experimental markets are also limited in that their failure to exhibit prolonged instability may be attributed to the compressed time span involved. It would be interesting to test the competing models by experimentally inducing longer time periods between decisions. And given the demonstrated importance of the particular trading institution on expectations, qualitatively different trading institutions might be explored.

\section{References}

Anderson, N.H., 1981. Foundations of information integration theory. New York: Academic Press.

Auster, R.D., 1970. The invariably stable cobweb model. Review of Economic Studies 37, $117-121$.

Blomqvist, H.C., 1983. On the formation of inflationary expectations: Some empirical evidence from Finland, 1979-1980. Journal of Economic Psychology 4, 319-334.

Carlson, J.A., 1967. The stability of an experimental market with a supply-response lag. Southern Economic Journal 33, 305-321.

Carlson, J.A., 1968. An invariably stable cobweb model. Review of Economic Studies 35, 360-363.

Cyert, R.M. and M.H. DeGroot, 1974. Rational expectations and Bayesian analysis. Journal of Political Economy 82, 521-536.

Einhorn, H.J. and R.M. Hogarth, 1985. Ambiguity and uncertainty in probabilistic inference. Psychological Review 92, 433-461.

Goodwin, R.M., 1947. Dynamical coupling with especial reference to markets having production lags. Econometrica 15, 181-204.

Lachman, R., J.L. Lachman and E.C. Butterfield, 1979. Cognitive psychology and information processing: An introduction. Hillsdale. NJ: Erlbaum. 
Lopes, L.L. and M.D. Johnson, 1982. Judging similarity among strings described by hierarchical trees. Acta Psychologica 48, 13-26.

Lovell, M.C., 1986. Tests of the rational expectations hypothesis. American Economic Review 76 , 110-124.

Lussier, D.A. and R.W. Olshavsky, 1979. Task complexity and contingent processing in brand choice. Journal of Consumer Research 6, 154-165.

Mansfield, E., 1975. Microeconomics: Theory and applications. New York: Norton.

Muth, J.F., 1961. Rational expectations and the theory of price movements. Econometrica 29, $315-335$.

Nerlove, M., 1958. Adaptive expectations and cobweb phenomena. Quarterly Journal of Economics $73,227-240$.

Neter, J. and W. Wasserman, 1974. Applied linear statistical models. Homewood, IL: Irwin.

Newell, A. and H. Simon, 1972. Human problem solving. Englewood Cliffs, NJ: Prentice Hall.

Oliver, R.L. and R.S. Winer, 1987. A framework for the formation and structure of consumer expectations: Review and propositions. Journal of Economic Psychology 8, 469-499.

Pashigian, B.P., 1970. Rational expectations and the cobweb theory. Journal of Political Economy $78,338-352$.

Payne, J.W., 1976. Task complexity and contingent processing in decision making: An information search and protocol analysis. Organizational Behavior and Human Performance 16 , 366-387.

Plott, C.R. 1982. Industrial organization theory and experimental economics. Journal of Economic Literature 20, 1485-1527.

Plott, C.R. and V.L. Smith, 1978. An experimental examination of two exchange institutions. Review of Economic Studies 45, 133-153.

Pruitt, S.W., R.J. Reilly and G.E. Hoffer, 1988. The effect of media presentation on the formation of economic expectations: Somc initial evidence. Journal of Economic Psychology 9, 315-325.

Smith, V.L., 1976. Experimental economics: Induced value theory. Americal Economic Review 66, $274-279$.

Tversky, A. and D. Kahneman, 1974. Judgments under uncertainty: Heuristics and biases. Science $185,1124-1131$.

Webley, P. and R. Spears, 1986. Economic preferences and inflationary expectations. Journal of Economic Psychology 7, 359-369.

Williams, A.W., 1987. The formation of price forecasts in experimental markets. Journal of Money, Credit, and Banking 19, 1-18.

Winer, R.S., 1985. A price vector model of demand for consumer durables: Preliminary developments. Marketing Science 4, 74-90. 